Reviews in Digital Humanities • Vol. 3, No. 1

\title{
Editors' Note: January 2022
}

Roopika Risam ${ }^{1}$, Jennifer Guiliano ${ }^{2}$, Amanda Licastro ${ }^{3}$, Dibya Roy ${ }^{4}$, Schuyler Esprit ${ }^{5}$

${ }^{1}$ Salem State University, ${ }^{2}$ IUPUI, ${ }^{3}$ University of Pennsylvania, Penn Libraries,

${ }^{4}$ Indian Institute of Technology Jodhpur, ${ }^{5}$ University of West Indies

Published on: Jan 11, 2022

DOI: $10.21428 / 3 e 88 f 64 f .8 f b c 9 f 57$

License: Creative Commons Attribution 4.0 International License (CC-BY 4.0). 


\section{Editors' Note}

Happy new year from Reviews in Digital Humanities!

We are delighted to be starting our third year of publication with a special issue on digital humanities pedagogy. This issue, co-edited by Amanda Licastro, Dibyadyuti Roy, and Schuyler Esprit brings together three editors from around the world to shed light on the diverse range of digital projects by and for students. With this issue, we continue working towards our goal of expanding the geographical purview of Reviews in $D H$ beyond the U.S. This year, look for special issues on Black Digital Humanities; Digital Race, Health, and Medicine; Digital Archaeology; and Black Atlantic Digital Humanities.

If you are interested in editing a special issue of Reviews, drop us a note! You can also submit a project for review, nominate a project you admire, volunteer for our reviewer pool, and tell your colleagues and students about the journal.

Questions? Thoughts? Concerns? Contact the editors, Jennifer Guiliano and Roopika Risam, by email or through the Twitter hashtag \#ReviewsInDH.

\section{Guest Editors' Note}

\section{Amanda Licastro, Dibyadyuti Roy, and Schuyler Esprit}

Does digital humanities scholarship inform our digital humanities pedagogies? Or is digital humanities pedagogy the generative bedrock around which localized and contextual humanistic inquiries about digital spaces, objects, and practices materialize? The editors of this special issue-emerging from diverse yet complementary intersectional positions-converged to consider these queries over the past few months. With a deliberate attempt to preclude any representative telos for the sites or epistemes we inhabit, we approached this special issue of Reviews in Digital Humanities as the beginning of a journey.

The role of teaching is undervalued in a system of higher education that privileges research and the products that result from that research. Both the process and products of teaching — course design, syllabi, assignments, and student work-are overlooked in academia, despite the significant impact of these materials in the ecosystem of higher education. This is especially true in the humanities, where teaching loads tend to be high and a large majority of courses are general education 
requirements taught to non-majors. In a market that simultaneously positions students as consumers and cheap labor, the intellectual work of students is often undermined, depreciating their efforts or reducing them to a numeric grade. However, digital humanities presents an opportunity to demonstrate the intervention and impact of pedagogical practice because many of the products are public-facing and interactive. Inspired by recent efforts to validate digital humanities pedagogy through formal publication, such as the edited collection Digital Pedagogy in the Humanities and journals such as the Journal of Interactive Technology and Pedagogy, we aim to bring awareness to the rich content created by students in higher education. By highlighting these projects, we hope to acknowledge that the shape and infrastructure of pedagogy in the context of the Global South(s) often fall outside the normative forms reflected in these U.S.-centric publications.

Being acutely aware that digital humanities and its pedagogy(ies) are shaped by the infrastructures, limitations, and affordances of our local contexts, we highlight projects that exemplify the chaotic yet productive potential of digitality, while also being alive to its various discontents. We believe that the projects here exemplify how digital humanities pedagogy must at its core focus on two key facets: empathy and engagement. With a keen eye toward the relational and not only geographical definitions of global digital humanities, this issue eschews authoritatively defining "digital humanities pedagogy." Instead the projects here are illustrative of the complex genealogies and overlaps between cultural connotations of digital pedagogy, often made invisible in normative digital humanities conversations.

In this issue we focus on projects that demonstrate the power of community-engaged, research-based digital humanities across contexts. Our intention is to showcase a range, both in terms of tools and scale, as well as a diversity in the production process from a variety of institutions across the globe. Some of the projects in this issue deploy open source and open access digital tools for project building, such as Omeka and WordPress. These are accessible for most undergraduate students entering the field while also being accessible in the Global South, where proprietary tools are cost prohibitive even when they are available within regions outside of the developed world. Participants adding content and updating infrastructure to sustain these digital spaces carefully over time raises questions about project sustainability. Given the realities of the Covid-19 pandemic, climate vulnerability, and the onslaught of disasters that threaten the Global South from the Caribbean to South Asia, we hope that these projects inspire creators and future digital humanities teachers and practitioners to think more deliberately about preserving the digital record. 
The projects in this issue include:

- The Penn \& Slavery_Project, an app and website investigating the University of Pennsylvania's relationship to slavery, directed by Kathleen Brown and reviewed by Elizabeth Losh;

- Indian Community Cookbooks, an archive of community cookbooks from India, directed by Khushi Gupta, Muskaan Pal, and Ananya Pujary and reviewed by Souvik Mukherjee;

- The Delek Archives, a blog documenting casteism and Islamophobia in Indian schools, directed by Titas Bose and Bhaswar Faisal Khan and reviewed by Arjun Ghosh;

- Baltimore Traces, a multimedia teaching project on Baltimore, directed by Nicole King and Bill Shewbridge and reviewed by Brandon Walsh; and

- Digital Oral Histories for Reconciliation, a virtual reality experience on the Nova Scotia Home for Coloured Children, directed by Kristina Llewellyn and reviewed by Jasmine Clark.

The richness of the student projects included in this issue has pushed the editors to call for illuminating the often-invisible labor of digital humanities project development, even within resource-rich institutions. Many of the critiques raised in the reviews found here could be potentially addressed through a page on process in these projects, perhaps a note of reflection where project creators can lay bare the experimental and transformative nature of digital humanities work in these specific circumstances. Perhaps this self-reflexive model of project development may become best practice through networked sites where both instructors and students think through their work together, or even with the inclusion of course syllabi as a menu option, elucidating the intellectual framework within which iterative student learning emerges. 